\title{
Improving the science-policy dialogue to meet the challenges of biodiversity conservation: having conversations rather than talking at one-another
}

\author{
Juliette C. Young • Kerry A. Waylen • Simo Sarkki • Steve Albon • \\ Ian Bainbridge $\cdot$ Estelle Balian · James Davidson • David Edwards • \\ Roddy Fairley • Ceri Margerison • Davy McCracken • Roger Owen • \\ Christopher P. Quine • Charles Stewart-Roper • Des Thompson • \\ Rob Tinch - Sybille Van den Hove $\cdot$ Allan Watt
}

Received: 16 September 2013/ Accepted: 20 December 2013/Published online: 8 January 2014

(C) The Author(s) 2014. This article is published with open access at Springerlink.com

\begin{abstract}
A better, more effective dialogue is needed between biodiversity science and policy to underpin the sustainable use and conservation of biodiversity. Many initiatives exist to improve communication, but these largely conform to a 'linear' or technocratic model of communication in which scientific "facts" are transmitted directly to policy advisers to "solve problems". While this model can help start a dialogue, it is, on its own, insufficient, as decision taking is complex, iterative and often selective in the information used. Here, we draw on the literature, interviews and a workshop with individuals working at the interface between biodiversity science and government policy development to
\end{abstract}

Electronic supplementary material The online version of this article (doi:10.1007/s10531-013-0607-0) contains supplementary material, which is available to authorized users.

J. C. Young $(\bowtie) \cdot$ A. Watt

NERC Centre for Ecology and Hydrology, Edinburgh, Midlothian EH26 0QB, UK

e-mail: j.young@ceh.ac.uk

K. A. Waylen · S. Albon

James Hutton Institute, Craigiebuckler, Aberdeen AB15 8QH, UK

S. Sarkki

Thule Institute, University of Oulu, P.O. Box 7300, 90014 Oulu, Finland

I. Bainbridge $\cdot$ R. Fairley $\cdot$ D. Thompson

Scottish Natural Heritage, Silvan House, 3rd Floor East, 231 Corstorphine Road, Edinburgh EH12 7AT, UK

E. Balian - R. Tinch - S. Van den Hove

Median, Carrer Vista Alegre 20, 08197 Sant Cugat del Valles, Spain

J. Davidson · R. Owen

Scottish Environment Protection Agency, Inverdee House, Baxter Street, Aberdeen AB11 9QA, UK

D. Edwards · C. P. Quine

Forest Research, Northern Research Station, Roslin EH25 9SY, UK 
present practical recommendations aimed at individuals, teams, organisations and funders. Building on these recommendations, we stress the need to: (a) frame research and policy jointly; (b) promote inter- and trans-disciplinary research and "multi-domain" working groups that include both scientists and policy makers from various fields and sectors; (c) put in place structures and incentive schemes that support interactive dialogue in the long-term. These are changes that are needed in light of continuing loss of biodiversity and its consequences for societal dependence on and benefits from nature.

Keywords Biodiversity conservation · Biodiversity policy · Decision-making ·

Knowledge $\cdot$ Science-policy interfaces $\cdot$ Sustainability

\section{Introduction}

Biodiversity continues to be lost at an alarming rate (Pereira et al. 2010). Our knowledge of biodiversity status and trends, and the drivers of change, has increased markedly and is highlighting where action is needed to improve biodiversity conservation efforts (e.g. Brooks et al. 2006). However, conservation and sustainable use of biodiversity continues to be allocated low importance compared to other policy challenges, leading to a perception that research on biodiversity is still under-used in decision-making and implementation (Spierenburg 2012).

Many initiatives already exist to tackle this perceived underuse of scientific knowledge. However, their design - and expectations of what they will achieve-often reflect an understanding of science-policy interfaces only as an overly simple process of transferring neutral facts to solve problems perceived by policy-makers (the 'linear model') (Nutley et al. 2007). There is ample evidence that transforming scientific evidence into 'usable knowledge' is neither automatic nor straightforward (Haas 2004; Knight et al. 2010; McNie 2007; Ozawa 1996; Rosenberg 2007). Indeed, as Vogel et al. (2007) remark, the reality is that all too often "the scientific output is more likely to be mismatched to user requirements, i.e. not what practitioners need; it may not be delivered in time or in appropriate formats; those interacting do not communicate well; scientists feel their credibility is negatively affected by collaborating with practitioners; stakeholders do not feel their legitimate concerns are addressed; and so on" (Vogel et al. 2007, p. 352).

The key challenge is to move beyond criticism of past efforts, and instead to provide constructive recommendations for actions that not only build on these efforts but also reflect a more nuanced understanding of science-policy dialogue. This paper aims to provide practical and accessible recommendations, aimed at different levels (from individuals and teams to organisations) intended to improve and promote conversations between science and policy sectors in the field of conservation and sustainable use of biodiversity. We combine insights from the literature, interviews and a workshop with

C. Margerison

British Ecological Society, Charles Darwin House 12 Roger Street, London WC1N 2JU, UK

D. McCracken

Scotland's Rural College, JF Niven Building, Aberdeen, Ayr KA6 5HW, UK

C. Stewart-Roper

Scottish Government, Victoria Quay, Edinburgh, EH6 6QQ, UK 
individuals connected with science-policy interfaces for biodiversity conservation and its sustainable use.

\section{Insights from the existing literature}

The 'linear model' of science-policy communication assumes that policy makers pose well-defined questions, scientists provide credible, legitimate, relevant and timely knowledge (Bradshaw and Borchers 2000; Cash 2001) and policy-makers will go on to develop solutions based on this knowledge (Habermas 1971; Pielke 2007). Following this linear model, science and policy advice/decision-making are perceived as separate domains, with science perceived as a uniquely neutral provider of objective knowledge (Van den Hove 2007; Wardekker et al. 2008), and decision-making the domain and responsibility of policy specialists (Demeritt 2006). This often leads to a focus on the packaging and presentation of scientific knowledge in order to promote its dissemination (Owens 2000), widely referred to as 'knowledge transfer'.

Though appealingly simple, and useful in some situations as a starting point to dialogue, the linear model has been criticised as being both inadequate as a description of actual science-policy processes, and inappropriate as an aspiration for effective dialogue (see Nutley et al. 2007; Van Kerkhoff and Lebel 2006). The view that there is a 'fully objective, independent and impartial domain of technoscience that experts can tap into' (Wynne et al. 2007, p. 77) — the only challenge being that they do so reliably — has been argued to be naïve for several reasons. First, research itself is not neutral and its commissioning and interpretation reflects societal values (Shaxson and Bielak 2012; Spierenburg 2012; Hoppe 2005). Second, policy processes are complex, multidimensional and unpredictable (Young 2007), incorporate multiple sources of information, not only scientific, and often use the latter selectively (Owens 2005). Third, knowledge is something better understood as socially constructed (co-production) (Cash et al. 2006) and there are important trade-offs in producing knowledge that is simultaneously credible, legitimate and relevant (Cash et al. 2003). For example, whilst there may sometimes be a case for rushing results to meet pressing policy demands thereby addressing their relevance, there is a risk this may impact on the quality of the science produced, its credibility and, in turn, the perceived credibility of the knowledge providers (Sarkki et al. 2013).

Taken together, these more nuanced views of science policy communication highlight the need to engage in two-way interaction (Lemos and Morehouse 2005), not solely focussing on packaging and presentation of information. This is important, as it is more effective to have a 'conversation'. Several authors have provided insights designed to encourage this (in particular see Nutley et al. 2007; Shaxson and Bielak 2012). These ideas focus on facilitating interactions and building interpersonal relationships, in order to provide knowledge and advice (Best and Holmes 2010; Van den Hove 2007), that may achieve many and varied eventual influences, not necessarily immediate and direct use (Rich 1997).

However, the design of many interventions is still thought to be influenced by the 'linear model' (e.g. Engels et al. 2006; Koetz et al. 2011). This includes initiatives related to environment knowledge and communication (Turnhout et al. 2008). The Global Biodiversity Assessment, for example, was a scientific document that had limited policy impact due to inadequate communication before, during and after its publication (Watson 2005). More recently, the development of the UK National Ecosystem Assessment paid less attention to processes of interaction than the literature would recommend (Waylen and Young). 
Furthermore, there are also specific challenges associated with communication on biodiversity issues, because the characteristics of biodiversity and environmental issues may make them particularly problematic to understand, communicate and resolve. Problems related to biodiversity and ecosystem services are often referred to as "wicked" problems (Churchman 1967; Sharman and Mlambo 2012), and include uncertainty, complexity, diverse values and the involvement of many sectors. These complex problems are likely to be particularly difficult to communicate (Rothman et al. 2009) and unlikely to have simple 'optimal' solutions (Laurance et al. 2012; Pielke 2007; Stirling 2010). The cross-sectoral nature of some conservation and environmental issues means that many policies are linked and contain multiple objectives, thereby adding to their complexity.

Interdisciplinarity has been recommended to better understand and address these challenges arising from this complexity (Young and Marzano 2010). However, moving beyond disciplinary boundaries is challenging (Bracken and Oughton 2009; Lowe et al. 2013). It is thought that a key barrier is "silo thinking" in both science (e.g. Lawrence and Després 2004; Norgaard 2004; Pohl 2008; Juntti et al. 2009; Farrell et al. 2013) and policy sectors (Haas 2004). Individuals in different 'silos' may have different interests (e.g. different policy sectors), and understandings (e.g. different disciplines), resulting in different motives for producing and using knowledge. Without integrated cross-sectoral and multi-level policy approaches, action required to address biodiversity issues will be hindered (e.g. Kay and Regier 2000; Fairbrass and Jordan 2004). It seems critical that any recommendations to improve science-policy communication also promote interdisciplinarity on the science side and cross-sectoral integration on the policy side.

To move forward from silo thinking in both science and policy, we linked theoretical observations with the experiences of over forty individuals directly engaged in sciencepolicy dialogue.

\section{Methods}

Three sequential approaches were used to synthesise experiences and identify recommendations: a literature review, interviews and a workshop.

First, a literature review was carried out to identify key challenges to science-policy dialogue, and existing ideas and recommendations. We focused on literature from the biodiversity conservation and environmental management literature as well as from science and technology studies. Challenges and recommendations from these sources were collated and used to inform topics and ideas discussed in semi-structured interviews with scientists and policy-makers.

Second, semi-structured interviews were used to explore experiences, views and perceptions of individuals involved in science-policy communication. The ideas from the literature informed a topic guide (see Supplementary material), that was used flexibly according to interviewee experiences and interests, and was iteratively updated based on previous interviews. Our interviews comprised four parts. First, we aimed to understand the role and background of interviewees. Second, we explored interviewees' experiences of accessing and communicating scientific knowledge. Questions were adapted according to the current focus of interviewees' work (based on the first part of the topic guide). For example, those interviewees working more in the policy sphere were asked about their experiences of accessing information, whereas those interviewees working more in the scientific sphere were asked about their experiences of communicating scientific knowledge. Third, we explored interviewees' perceptions of current knowledge in biodiversity 
Table 1 Simple categorisation of interviewees who contributed to this study

\begin{tabular}{lllll}
\hline Users and/or producers of knowledge & & Local & National & International \\
\hline Knowledge producers & P1-P9 & P1-P4 & P4-P9 & P8-P9 \\
Knowledge users & U1-U12 & U1-U3 & U3-U12 & U12 \\
Knowledge producers and users & PU1-PU4 & PU1-PU2 & PU2-PU4 & PU3-PU4 \\
Total & $\mathbf{2 5}$ & $\mathbf{9}$ & $\mathbf{1 9}$ & $\mathbf{5}$ \\
\hline
\end{tabular}

The first letter refers to whether interviewees were mainly knowledge producers $(\mathrm{P})$, knowledge users (U) or both (PU). The three last columns specify the scale at which interviewees worked to communicate. Some interviewees worked at different scales (e.g. national and international)

and ecosystem services, and its uptake (again, the focus was slightly adapted depending on the role of interviewees as identified in the first part of the topic guide). Lastly, we explored issues of dialogue and co-construction.

We conducted a total of 25 semi-structured interviews in the summer of 2011 with a range of individuals working at the science-policy interface. Our sample was designed to capture the views of a range of potential 'users' (usually from the policy or decision-taking community) as well as 'producers' of knowledge (usually from the scientific community) along a local-international gradient, from local-level interactions, through to interactions at the international level (e.g. The Intergovernmental Platform for Biodiversity and Ecosystem Services-IPBES). For a categorisation of interviewees, see Table 1.

The interviews were recorded and transcribed verbatim for qualitative analysis, using the software programme Nvivo 9 to manage, code and analyse the data (QSR International 2010). The use of qualitative research and interview data has been shown as a useful way to explore individuals' perceptions and processes relevant to understanding knowledge use (e.g. Holmes and Clark 2008; Turnhout et al. 2013). In qualitative analysis, coding means carefully reading and demarcating sections of the data according to what they represent: each code represents one concept, and multiple codes can be applied to one piece of data. This subsequently allows systematic recall of all data 'coded' for a certain concept, and complex queries to be performed to explore relationships between concepts, thus aiding the researcher to comprehensively explore and interrogate patterns within the data (Boyatzis 1998). During the coding stage we initially used an iterative and inductive approach influenced by grounded theory (Strauss and Corbin 1998) to identify our themes, and then applied more deductive themes from the literature to compare emerging interpretations with previous ideas (Strauss and Corbin 1998). We use verbatim quotes from our transcripts to illustrate key themes in our data. To protect interviewee confidentiality, such quotes are anonymised. From the interviews, a draft set of recommendations on how to improve science-policy dialogue was developed.

The last stage of research was to discuss, test and refine these recommendations in a workshop setting. In June 2012, a workshop with 18 individuals engaged in a variety of roles within the science and policy sectors convened to discuss challenges in and recommendations for improved science-policy dialogue. Attendees received beforehand the draft recommendations arising from the interviews and discussion at the meeting focused on critiquing these ideas and identifying key underlying themes. A report from the workshop was circulated to participants and provided further opportunities for feedback to refine the ideas and ensure their accessibility. 
The resulting recommendations, discussed in more detail in the following sections, give an overview combined from existing good practice, individual ideas and experiences, and collective discussion.

\section{Recommendations for improving science policy dialogue}

As stated in the section above, the packaging and presentation of scientific knowledge to promote its dissemination, widely referenced as 'knowledge transfer', can be a starting point to dialogue. As such, Tables 2 and 3 outline some of the practical recommendations aimed at individuals, teams and organisations, based on experiences of interviewees, to improve knowledge transfer.

To promote real conversations between science and policy and co-construction of problems and solutions, however, it is not enough to adopt specific piecemeal recommendations. Fundamental changes in science and policy are required, as outlined below.

Framing research and policy jointly

Not all research will be directly policy-relevant, and conversely some research will prove unexpectedly relevant. However, for research that aims specifically to answer user needs, framing the problem, research process and solutions jointly with science and policy may improve the likelihood of useful and relevant research outputs. Framing is understood here as "the interpretation process through which people construct and express how they make sense of the world around them" (Gray 2003, p. 12).

The interviewees and workshop participants emphasised strongly the need to change how problems are framed and agreed. This is crucial as it influences the way in which research will be carried out and presented, and thus the potential for research outputs to be used in decision-making processes. Indeed, one workshop participant suggested that disciplinary silos and research outputs poorly adapted to users' needs were often the direct results of poorly framed questions. A recent review of the use of economic valuation for decision-making also highlighted this very problem: without potential research uses being made explicit or contextualised, the tools offered to decision-makers may not match their expectations or needs (Laurance et al. 2012).

The fact that questions are often not framed by science and policy jointly is in part due to the way in which funding agencies currently work. It is unusual for research questions to be framed jointly with the potential users of that research. However, some initiatives, such as the European Platform for Biodiversity Research Strategy (EPBRS), have been operating in this way. EPBRS used a range of methods to frame research priorities. The usual process has involved, as a first step, an e-conference open to all, focussing on a specific topic, usually an emerging and/or pressing issue related to biodiversity. Such e-conferences included keynote contributions, usually from scientists, but also from a range of policymakers and other stakeholders who could contribute their specific needs to the debate. The results of the e-conferences have then been compiled and communicated at EPBRS plenary meetings, attended by policy-makers and scientists (usually working on the topic that was the theme of the e-conference and plenary) from each EU Member State. Discussing research and policy issues together has often led to the identification of potential points of connection, and common shared problems, such as policy "problems" that required a new approach. The outputs of the plenary meeting have been lists of research recommendations, jointly framed by policy and science, which could then be fed into EU and national level funding mechanisms. 


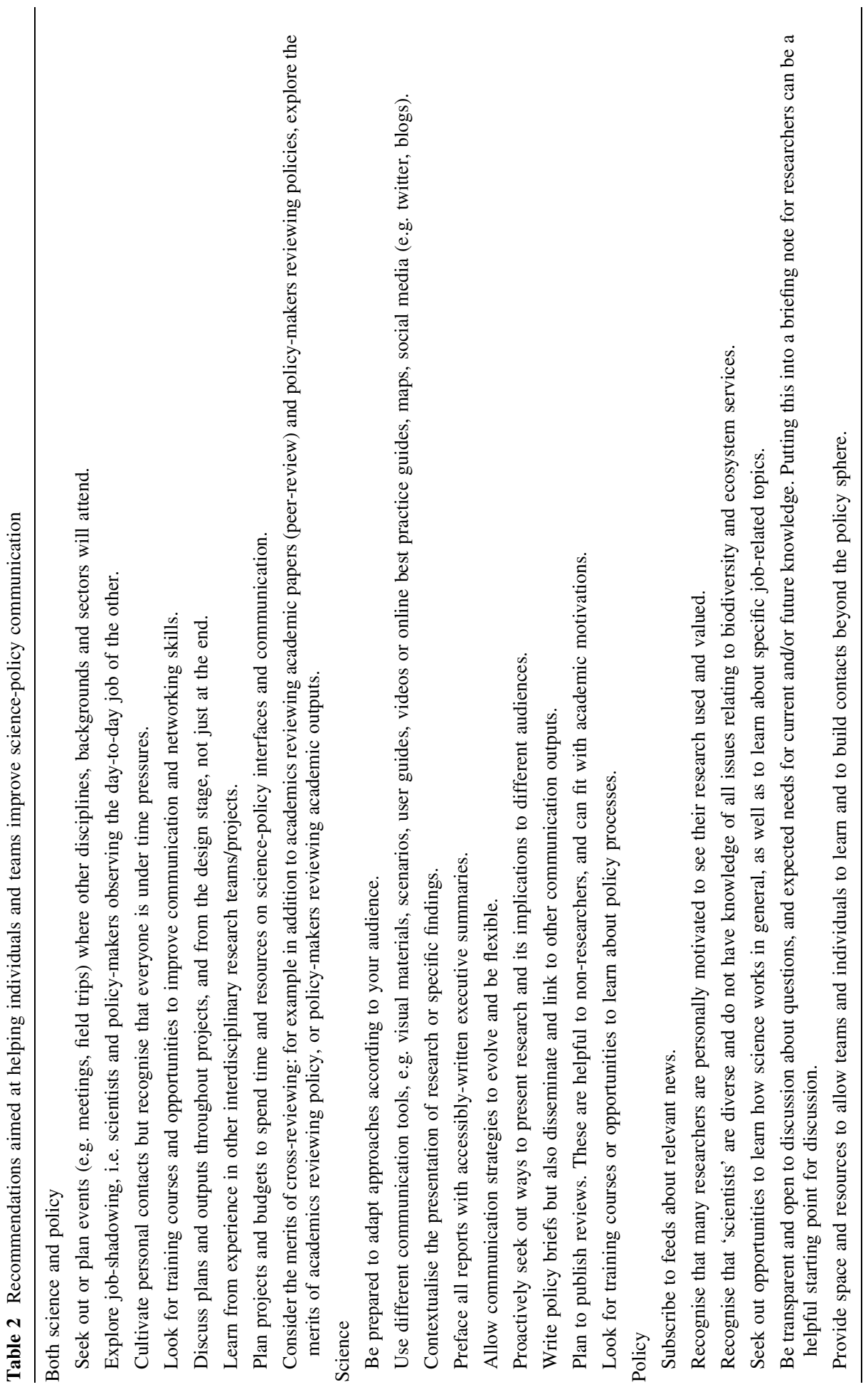




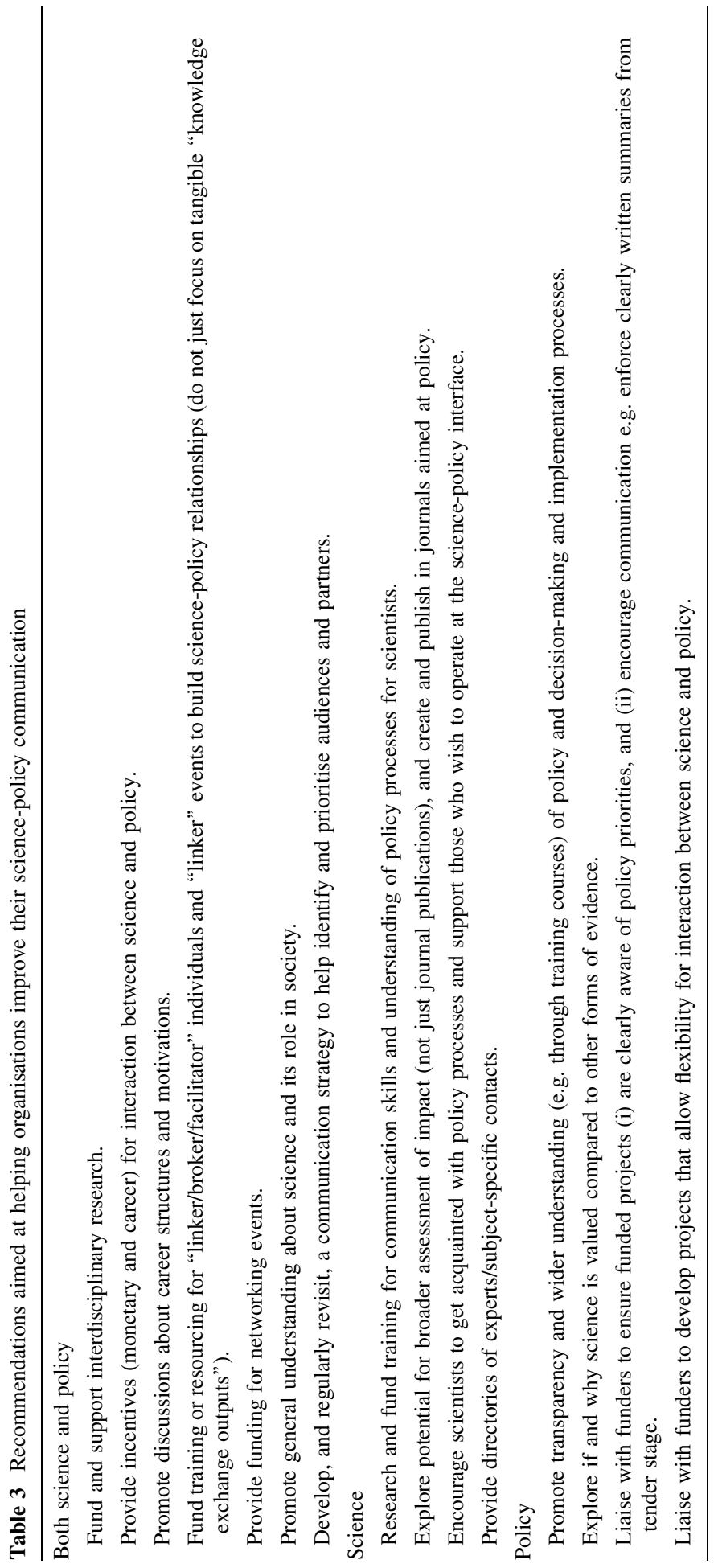


Processes such as the EPBRS, that encourage the framing of problems or questions jointly with producers and users of research, could be used as an example for funding agencies wanting to move beyond silos in science and policy and delivering research outputs matching policy expectations and needs.

Funding should be focused on cross-cutting issues and could be fostered through mechanisms that require groups that would not normally come together to do so, e.g. EU research programmes, multi-funder thematic programmes and, potentially, the research that will be triggered by the IPBES. Policy mainstreaming should also be encouraged, for example by seeking and promoting governmental mandates for various policy sectors to take biodiversity and ecosystem services into account, and also through "multi-domain" working groups that include both scientists and policy makers from various fields and sectors.

Following on from the joint framing of the problem and questions, it is then essential to ensure that overall research designs adapt to and remain engaged with relevant users or policy sectors. This will require more transparency on the part of science and policy. More inclusive research processes will require more honest conversations about the processes and judgements that feed into the practice of science. Scientists often want to maintain their own view about what constitutes science, and present results in a corresponding format. This view of science emphasises objective and value-free science, preference for technical solutions, and advancement of scientific method and rationality as preferred logic (Cortner 2000). Such a view is quite different from ideas of blurred and co-evolving science-policy (e.g. Guston 1999), post-normal science (Funtowicz and Ravetz 1993) or 'mode 2' science (Nowotny et al. 2001), and does not tally well with complex and uncertain biodiversity problems. Similarly, decision-makers will need to be more transparent about how decisions are made, and how and when scientific knowledge is used by policy-makers. Scientists often perceive that scientific knowledge makes up a large part of the foundation of the decision-making process. In reality, scientific knowledge may only be a small component of the policy process. This is not necessarily a problem, as long as policy makers are transparent in their decision-making processes, sharing their views, interests and concerns with scientists, to help frame research plans that are mutually engaging, useful and relevant. A policy-maker who had had experience of such a process remarked "it's resource well spent to spend the time with the scientists agreeing the method and helping steer the work" (U3). Increased collaborations with policy-makers during the research process can also decrease the problems of value-laden science, by opening up uncertainties and promoting inclusiveness in knowledge production (Pielke 2007). Developing briefing notes for researchers was suggested as a potentially useful starting point for discussions, as were the requirement for a (funded) synthesis of the evidence at the start of research projects and a science-policy interface strategy (Young et al. 2013).

Although research may start as a direct response to a policy need, research processes can stray off the policy need as it progresses. Regular discussions and meetings may be required to check that research is still aligned to the policy problem(s). Similarly, policy needs and views will change over time. Whilst it will not always be possible or appropriate for research plans and outputs to neatly 'fit' with evolving policy needs and thinking, keeping in close contact throughout the course of a project can help to identify where engagement can be made. Similarly, policy needs and thinking may need to change in response to scientific understandings and insights from research. This co-production of knowledge during the research process may, in turn, lead to a sense of commitment and 
ownership of the research and its results for those producing, funding and using the research (Lövbrand 2011) and potentially better research outputs and policies.

One interviewee suggested the development of an in-built evaluation of the research process, its outputs, and the way in which results were communicated incorporated into the research design. The evaluation could include feedback from potential users of the research. In addition, the evaluation could include lessons from other experiences and practices. This was perceived to have the potential to provide useful 'good practice' lessons for future policy- or society-relevant research processes. Finally, consideration should be given to the merits of cross-reviewing: for example in addition to academics reviewing academic papers (peer-review) and policy-makers reviewing policies, the merits of academics and other stakeholders reviewing policy, or policy-makers and other stakeholders reviewing academic outputs should be explored. Within academia, for example, the reviewing process (for quality assurance of science) is done by an author's peers in the scientific community. Whilst this should not be ignored, there may be some benefits of having scientific work reviewed by peers within other communities (e.g. other scientific disciplines or Schools, policy, NGOs, etc.) (Funtowicz and Ravetz 1993). These actors could evaluate the scientific outputs critically to make these more policy-relevant if possible. This type of reviewing would also address some of the interviewees' comments on the potential lack of feedback from funders on contracted research reports at the end of projects. However we note that as cross-reviewing is time consuming for all involved, planning and funding cross-reviewing initiatives would need to be recognised and resourced accordingly.

Finally, the whole process of framing the questions and research process jointly is likely to lead to a better understanding of the types of outputs useful for policy, namely outputs that are presented in the right format, using understandable language, in a timely way and addressing the institutional level (e.g. global, European, national, regional, organizational, team, individual) relevant for the given knowledge users.

The framing of science and policy can also be instrumental in strategic and long-term planning. Lack of coordinated planning between science and policy can lead to 'closed' thinking and a focus on immediate priorities for policy, without regard to identifying and acting on emerging and/or long-term issues. The lack of a strategic, long-term overview from policy and, in turn, science, may risk wasting resources and also risks duplicating previous work commissioned or carried out, particularly for small or applied projects. Moreover, institutional organisation of science may induce researchers to focus on improving knowledge on already well-studied topics rather than exploring new themes (Grandjean 2013).

Supporting joint strategic thinking explicitly_including work on long term visions for sustainability-can help to identify opportunities to connect science and policy agendas, lead to a better understanding of what science might be able to offer within a particular timeframe, and reduce the risks of neglecting emerging issues. Joint horizon scanning and scenario-planning tools developed with science and policy may help in thinking strategically about long term futures, and inform longer term policy agendas (Peterson et al. 2003).

Promoting inter- and trans-disciplinary research

As a first step to improved dialogue, organisations and funders have a role in promoting integrated knowledge. This involves gaining the most comprehensive knowledge on particular issues, which means integrating different knowledges to gain the best possible input 
to policy action. This means more collaboration within and amongst disciplines, often through interdisciplinary projects. Although the rhetoric of funding of research projects is increasingly putting an emphasis on interdisciplinarity, all too often, different disciplines working on the same project actually focus on their own 'sub-projects' with little interaction between groups of different disciplines. There needs to be more fundamental integration by building up relationships across disciplines and understanding of the methods and approaches used in each scientific discipline. This could be achieved, for example, through interdisciplinary conferences, interaction between junior and senior scientists to share experiences and discuss novel ideas and, more fundamentally, by changing the way in which research is commissioned to promote interdisciplinarity, thereby providing more robust and credible knowledge.

In addition to interdisciplinary research, more support from organisations and funders is needed to promote transdisciplinary research. By transdisciplinary approaches we understand work that "moves beyond the domain of disciplinarity, generating new approaches to scientific knowledge production that either transcend the formalism of a discipline altogether and/or operationalize integrative collaborations between academics and non-academics, such as local communities and/or policy-makers, as a core part of the scientific work" (Farrell et al. 2013), p. 36. Whilst this demands resources, “...quite often earlier involvement of these other groups actually improves the research or improves the relevance of the research you're doing in the first place". Improved engagement between science, policy and society may also mean that in the long-term real "problems" affecting society are more easily identified, and prioritised.

Transdisciplinary approaches that include collaborations with other stakeholders means a major shift in the way in which many scientists and policy-makers work, providing potential options and trade-offs, clarifying and making explicit (unavoidable) value judgements (Cortner 2000; Lubchenco 1998). There is little doubt that science needs to be more visible and its processes better understood, not just by the policy communities in terms of developing effective policies, but by society as a whole. This is necessary to justify and encourage continued funding towards the scientific research that is essential for the transition to sustainability. Scientists, as key knowledge-holders, are well placed to make science, the scientific process and its potential benefits to society more visible. All fora need to be exploited to make this science more accessible, including conferences, articles in different media, and activities with interested communities such as science festivals, 'café scientifique' etc. Personal meetings and talks with interested communities and groups can be helpful in promoting links and understanding in any group from business partners through to NGOs and civil society groups. This should ultimately contribute to a wider understanding and reasonable expectations of what science can and cannot deliver.

\section{Establishing incentives}

The above section highlight that individuals, or at least some members within a research or policy team, need to be prepared to engage in diverse opportunities for dialogue. These activities should be valued and carried out by individuals and teams on both sides of the science and policy divide. This requires increased resources and incentives from institutions and funders to recruit, train and encourage both scientists and policy-makers to engage with each other and with counterparts from other disciplines, as well as with the media and popular audiences.

Examples of possible incentives for individuals suggested by interviewees included publication citation metrics (Hirsch 2005) that incorporate grey literature, resulting in high 
impact scores for outputs aimed at policy-makers. Other incentives could include career recognition. Indeed, Holmes and Clark (2008) argue that strengthening interpretation capacity of scientists and policy makers should be done by providing attractive career paths. Such an example, suggested by workshop participants, was the esteem attached to being part of expert groups (in science and policy). Such experts could be called upon to provide information in particular policy areas, identify potential new research avenues, or suggest other experts.

In addition to the above incentives, organisational support for these staff could be aided by the development of organisations' communication and interface strategies, particularly if these strategies included an explicit recognition of the need for greater engagement of scientists and policy-makers.

Finally, an acknowledgement and promotion of boundary work (e.g. Guston 1999; Hellström and Jacob 2003; White et al. 2010) or knowledge brokerage (Pielke 2007) is needed to break the silo thinking in science and policy and enhance cross-domain dialogue. Indeed, Konijnendijk (2004) argues that failure of scientific knowledge to reach policy makers is often due to a lack of translators who can convey the message across the two spheres. One scientist went further and called for " a new cadre of people [...] it's not sufficient to identify there is an interface [between science and policy] it's who lives in that interface. And right now, no one lives in it, it's a no person's land" (PU3).

The main role of these translators was seen by some participants as condensing information to deliver accessible, clear and robust messages. In addition, translators could go further and help scientists understand better the complex and fuzzy policy making context, and open the complexities of biodiversity and ecosystem services issues to policy makers (Cash and Moser 2000). This could be done for instance by arranging sessions to familiarize policy makers with models and concepts developed by scientists (Haas 2004), and familiarising scientists with the needs and constraints of policy-makers (an example is that of the problems of communicating uncertainty). One such individual therefore described his role as "actually understanding what the question is and what the person wants to try to do...the point the person is trying to make, you need to be able to hear that and translate that, and then to be able to read the facts and translate those and try and marry the two together" (U4). They have a key role therefore in overcoming the language boundaries on both sides and linking communities-leading one participant to note the potential of having science translators talking to policy translators.

Within research organisations such individuals may be knowledge exchange specialists, or within policy departments these may be specialist scientific advisors. The challenge could be training or recruiting scientists who have high profiles within their own disciplines and who are able to efficiently communicate with counterparts from other disciplines, as well as with the media, policy makers, and popular audiences (Haas 2004). 'Translation' roles are, however, at present not always formally recognised or rewarded. The organisational support of these staff would be partly aided by the development of organisations' communication strategies, which would outline their objectives and their timescales for various information needs. These strategies will of course vary according to the organisation's outputs and strengths, and will need to reflect different priorities over time.

However, the existence of translators (also called mediators or linkers) should not (and could not) absolve individuals in science and policy from having some role to play in seeking out translation, dialogue, learning and sharing opportunities. Otherwise, a risk is that dialogue can become overly vulnerable to the continuity of key personnel. The challenge will be to promote translators, but also train and incentivise scientists and policy makers wanting to engage themselves in translation roles in addition to their scientific and policy roles. 


\section{Discussion and conclusions}

Failures of biodiversity science-policy communication persist due to misunderstandings, sometimes unrealistic expectations of how science and policy should operate and interact (Jasanoff 1987), and the complex 'wicked' nature of biodiversity problems (Sharman and Mlambo 2012). As such, initiatives to improve science-policy interfaces must reflect the multifaceted and multi-layered complexity of science and policy communication. There is little prospect of these becoming less messy, or that the challenges will vanish simply by persevering in better presenting and packaging facts better (the current focus of much effort-Nutley et al. 2007).

In this paper, we reframed the many existing critiques and insights (e.g. Dilling and Lemos 2011; Shaxson and Bielak 2012), stressing the importance of working across both scientific disciplines and policy sectors, in order to foster joint framing of issues, processes and outcomes. This will require creativity and resources, as well as a rethink in terms of 'indirect' science-policy links, namely the role of actors other than scientists and policymakers in shaping the way biodiversity research is carried out and contributes to policy processes. Whilst some others have touched on this (e.g. Juntti et al. 2009; Laurance et al. 2012; Roux et al. 2006; Sutherland et al. 2009), we go further in recommending specific actions that will improve dialogue and ensuing action. In particular, we highlight the need for high-level changes to train, support and incentivise those scientists and policy actors enthusiastic about crossing boundaries and carrying out activities at the science-policypublic interface (Choi et al. 2005). These institutional and sectoral changes are needed in order that science and policy dialogue activities are better supported and acknowledged as strengthening scientific excellence and policy decisions.

The problem of loss and unsustainable uses of biodiversity is such that there is an urgent need for such improved dialogue. For the remainder of this section, we wish to focus on identifying the steps needed to achieve this, namely:

(1) How to take into account loss and unsustainable uses of biodiversity as a specific issue requiring improved science-policy conversations

(2) How research can help identify and reach the most relevant target groups regarding biodiversity; and

(3) How policy makers, economic interest groups, other stakeholders and the public can better acknowledge, understand and use biodiversity knowledge

The loss of biodiversity and ecosystem services poses particularly intractable challenges, that require improved science-policy conversations. A first challenge is that biodiversity, with the exception of charismatic species, is not always visible or salient to publics or policy makers. This may result in people considering the biodiversity issue as being irrelevant to them. Thus, we need to continue to spell out the relevance of biodiversity to both publics and policy sectors. This could be done for example by focusing on ecosystem services, or the benefits of nature to people underpinned by biodiversity. Such an approach, however, entails risks linked to excessive commodification of nature and would need to be contextualised for different groups of stakeholders. A second challenge is that the problem of biodiversity loss is caused by a complex set of issues working at different levels. Recommendations about communication normally emphasise simplicity, but we argue that communication about biodiversity loss needs to incorporate or stress this complexity. Some argue that frameworks such as the drivers, pressures, state, impacts, responses (DPSIR) approach could help to map the complex picture of issues linked to 
biodiversity and make this complexity more understandable and further manageable (see Rounsevell et al. 2010). This would, however, need to be complemented by defining concrete and potential policy recommendations (the 'responses' in the DPSIR framework) that could be employed to tackle problems. The third challenge is that biodiversity loss is a multi-dimensional problem that neither ecological science or environmental policy can solely address. The problem of working in "silos", as outlined earlier in this paper, does not help to tackle such problems. To understand and act for conservation and sustainable uses of biodiversity requires transdisciplinary approaches where various disciplines, stakeholders as well as policy makers take part in the co-construction of knowledge. However, moving beyond silos is not just a challenge for scientists but also for policy: policy sectors other than just the environmental policy sector need to integrate biodiversity into their core focus areas. Only in this way will the complexities associated with biodiversity and its loss be taken into account to a sufficient extent by the wider policy community.

The acknowledgement of heterogeneous policy communities raises a fundamental question for biodiversity-related science-policy interfaces, namely how to identify and reach the most relevant target audiences. Biodiversity scientists may need to step onto uncomfortable ground, away from their favourite decision-makers in environmental policy sectors, for example by targeting also departments or sectors responsible for economic policies which are partly responsible for biodiversity loss. The basic message in the literature, and influencing our recommendations, is about the importance of jointly constructing knowledge and bringing together the scientific, institutional or policy knowledge. Thus, dialogue should be initiated with different target audiences, with special attention paid to other sectors that may be less familiar to biodiversity scientists, such as economic sectors and interest groups. There are ways to reach these groups. Firstly, biodiversity researchers could try to impact on the private actors by first altering the views of the related policy makers to implement top-down policies. This is unlikely until biodiversity is fully 'mainstreamed' across policy sectors. Secondly, biodiversity researchers need to include science-private actor dialogues as part of their agenda, and engage with these stakeholders, perhaps with the help of translators. For example, The Economics of Ecosystems and Biodiversity (TEEB) has a specific report aimed solely at businesses. Here economic benefits (and costs) resulting from biodiversity could be highlighted, for example by emphasising that responsible practice is a competitive advantage, or by stressing synergies for example between biodiversity conservation and tourism. Thirdly, the discussions about science following policy 'demand' could be extended to consider knowledge demand by the private sector. This is everyday practice in, for example, technical engineering projects. There is no reason why biodiversity research should not be influenced by the knowledge demand from economic actors and other private actors. One example of how private sector actors or high level policy makers (also hard to reach, but relevant for biodiversity) could be reached would be to arrange job-shadowing of these actors by scientists or translators who could then better understand the decision-making realities these actors are facing and as a result be able to better tailor the knowledge for specific purposes. Furthermore, this would provide opportunities for scientists to prove the usability of their knowledge in the everyday decision-making contexts faced by policy-makers and private actors.

One last final challenge is how to increase the salience of research and engagement for policy and other target audiences. Recommendations often emphasise the need for scientists to act differently in order to promote dialogue, but dialogue requires a two-way interest and commitment. Co-production entails that knowledge is produced via iterative two-way interactions between science and policy. Opportunities to promote such 
interaction between scientists and policy, from an early stage in any process, will help to create a sense of interest and commitment in all actors engaged (Lövbrand 2011). Results of this interaction would be joint problem definitions, enabling the production of knowledge perceived as politically relevant yet also scientifically interesting. Research funders can promote this by requiring dissemination not only at the end of projects but discussion about problems at the beginning of the projects and/or when designing research programmes. Thus, emphasis would shift from dissemination of results towards continuous engagement as stressed by our previous observations about co-framing. We earlier identified that policy makers' lack of transparency regarding the way they make decisions can be a serious barrier to interaction. If scientists do not understand the realities of decisionmaking they will be unlikely to produce relevant and suitable knowledge fit for purpose. Therefore, there is a need for incentives for policy-makers to communicate their processes and priorities to scientists. Here again, opportunities for networking and personal contact between scientists and policy makers could help to gain better understanding of the realities of decision-making. Our work also suggests that the specific technique of "crossreviewing' can help potential audiences for specific research processes perceive the outputs as more relevant and credible, and generally help target audiences familiarize themselves with messages from biodiversity research. Summaries, preliminary insights or mid-term results could be presented to policy actors for comment, thus enabling interaction throughout a research process and breaking down the time commitment over the duration of a project.

Our recommendations provide an ambitious but realistic approach to improving science-policy dialogue at all levels, from individuals and teams to organisations and funders. This will require more incentives for individuals to improve the way in which science and policy operate and interact, increased transparency, real and high quality inter- and transdisciplinary research, and strategic long-term visions. All this will be dependent on significant changes in training, supporting and incentivising those scientists and policy actors enthusiastic about crossing boundaries and carrying out activities at the science-policysociety interface. A genuine move away from silo approaches is science and policy is needed to begin building alliances between science, policy and ultimately society. Only then will we see the increase in the quality of both science and decision-making needed to address the societal and environmental challenges of the twenty-first century.

Acknowledgments We thank all the interviewees who took part in this work and constructive comments from anonymous reviewers. This research was supported by SPIRAL "Science Policy Interfaces for Biodiversity Research Action and Learning", an interdisciplinary research project funded under the European Community's Seventh Framework Programme, contract number: 244035. Kerry Waylen was co-funded by the RESAS Scottish Government 2011-2016 Strategic Research Programme.

Open Access This article is distributed under the terms of the Creative Commons Attribution License which permits any use, distribution, and reproduction in any medium, provided the original author(s) and the source are credited.

\section{References}

Best A, Holmes B (2010) Systems thinking, knowledge and action: towards better models and methods. Evidence \& Policy 6(2):145-159

Boyatzis RE (1998) Transforming qualitative information: thematic analysis and code development. Sage, London 
Bracken LJ, Oughton EA (2009) Interdisciplinarity within and beyond geography: introduction to special section. Area 41(4):371-373

Bradshaw GA, Borchers JG (2000) Uncertainty as information: narrowing the science-policy gap. Conserv Ecol 4(1):7

Brooks TM, Mittermeier RA, da Fonseca GAB, Gerlach J, Hoffmann M, Lamoreux JF, Mittermeier CG, Pilgrim JD, Rodrigues ASL (2006) Global biodiversity conservation priorities. Science 313(5783): 58-61

Cash DW (2001) 'In order to aid in diffusing useful and practical information': agricultural extension and boundary organizations. Sci Technol Human Values 26(4):431-453

Cash DW, Clark WC, Alcock F, Dickson NM, Eckley N, Guston DH, Jäger J, Mitchell RB (2003) Knowledge systems for sustainable development. Proc Natl Acad Sci USA 100(14):8086-8091

Cash DW, Borck JC, Patt AG (2006) Countering the loading-dock approach to linking science and decision making. Sci Technol Human Values 31(4):465-494

Cash DW, Moser SC (2000) Linking global and local scales: designing dynamic assessment and management processes. Glob Environ Chang 10:109-120

Choi BCK, Pang T, Lin V, Puska P, Sherman G, Goddard M, Ackland MJ, Sainsbury P, Stachenko S, Morrison H, Clottey C (2005) Can scientists and policy makers work together? J Epidemiol Community Health 59(8):632-637

Churchman C (1967) Wicked problems. Manage Sci 4(14):141-142

Cortner HJ (2000) Making science relevant to environmental policy. Environ Sci Policy 3(1):21-30

Demeritt D (2006) Science studies, climate change and the prospects for constructivist critique. Econ Soc 35:453-479

Dilling L, Lemos MC (2011) Creating usable science: opportunities and constraints for climate knowledge use and their implications for science policy. Glob Environ Chang 21(2):680-689

Engels A, Hisschemöller M, von Moltke K (2006) When supply meets demand, yet no market emerges: the contribution of integrated environmental assessment to the rationalisation of EU environmental policymaking. Sci Public Policy 33:519-528

Fairbrass J, Jordan A (2004) Multi-level governance and environmental policy. In: Bache I, Flinders MV (ed) Multi-level governance. Oxford University Press, Oxford, pp 147-164

Farrell K, Van den Hove S, Luzzati T (2013) What lies beyond reductionism? Taking stock of interdisciplinary research in ecological economics. In: Farrell K, Luzzati T, Van den Hove S (ed) Beyond Reductionism: a passion for interdisciplinarity. Routledge studies in ecological economics. Routledge, London

Funtowicz S, Ravetz J (1993) Science for the post-normal age. Futures 25(7):735-755

Grandjean P (2013) Science for precautionary decision-making in: EEA, Late lessons from early warnings: science, precaution, innovation. EEA Report N 1/13

Gray B (2003) Framing of environmental disputes. In: Lewicki RJ, Gray B, Elliott M (ed) Making sense of intractable environmental conflicts. Island Press, Washington DC, pp 11-34

Guston D (1999) Stabilizing the boundary between politics and science: the role of the office of technology transfer as a Boundary Organization. Soc Stud Sci 1(11):87-111

Haas PM (2004) When does power listen to truth? A constructivist approach to the policy process. J Eur Public Policy 11(4):569-592

Habermas J (1971) Towards a rational society. Student process, science and politics. Beacon, Boston

Hirsch JE (2005) An index to quantify an individual's scientific research output. Proc Natl Acad Sci USA 102(46):16569-16572

Hellström T, Jacob M (2003) Boundary organizations in science: from discourse to construction. Sci Public Policy 30(4):235-238

Holmes J, Clark R (2008) Enhancing the use of science in environmental policy-making and regulation. Environ Sci Policy 11(8):702-711

Hoppe R (2005) Rethinking the science-policy nexus: from knowledge utilization and science technology studies to types of boundary arrangements. Poiesis \& Praxis: Int J Technol Assess Ethics Sci 3(3):199-215

Jasanoff SS (1987) Contested boundaries in policy-relevant science. Soc Stud Sci 17(2):195-230

Juntti M, Russel D, Turnpenny J (2009) Evidence, politics and power in public policy for the environment. Environ Sci Policy 12:207-215

Kay J, Regier H (2000) Uncertainty, complexity, and ecological integrity: insights from an ecosystem approach. In: Crabbé P, Holland A, Ryszkowski L, Westra L (ed) Implementing ecological integrity: restoring regional and global environmental and human health. Kluwer, Alphen aan den Rijn, pp 121-156 
Knight AT, Bode M, Fuller RA, Grantham HS, Possingham HP, Watson JEM, Wilson KA (2010) More action not more data. Science 9:141

Koetz T, Farrell KN, Bridgewater P (2011) Building better science-policy interfaces for international environmental governance: assessing potential within the Intergovernmental Platform for Biodiversity and Ecosystem Services. Int Environ Agreements 12(1):1-21

Konijnendijk CC (2004) Enhancing the forest science-policy interface in Europe: Urban forestry showing the way. Scand J For Res 19(4):123-128

Laurance WF, Koster H, Grooten M, Anderson AB, Zidem PA, Zwick S, Zagt RJ, Lynam AJ, Linkie M, Anten NPR (2012) Making conservation research more relevant for conservation practitioners. Biol Conserv 153:164-168

Lawrence R, Després C (2004) Special issue on transdisciplinarity. Futures 36(4):1-28

Lemos MC, Morehouse BJ (2005) The co-production of science and policy in integrated climate assessments. Glob Environ Chang 15:57-68

Lövbrand E (2011) Co-producing European climate science and policy: a cautionary note on the making of useful knowledge. Sci Public Policy 38(3):225-236

Lowe P, Phillipson J, Wilkinson K (2013) Why social scientists should engage with natural scientists. Contemporary Social Science. J Acad Soc Sci 8(24):324. doi:10.1080/21582041.2013.769617

Lubchenco J (1998) Entering the century of the environment: a new social contract for science. Science 279:491-497

McNie EC (2007) Reconciling the supply of scientific information with user demands: an analysis of the problem and review of the literature. Environ Sci Policy 10(1):17-38

Norgaard RB (2004) Learning and knowing collectively. Ecol Econ 49:231-241

Nowotny H, Scott P, Gibbons M (2001) Re-thinking science. Knowledge and the public in an age of uncertainty. Blackwell, Cambridge

Nutley SM, Walter I, Davies HTO (2007) Using evidence: how research can inform public services. Policy Press, Bristol

Ozawa CP (1996) Science in environmental conflicts. Sociol Perspect 39(2):219-230

Owens S (2000) Engaging the public: information and deliberation in environmental policy. Environ Plan A $32: 1141-1148$

Owens S (2005) Making a difference? Some perspectives on environmental research and policy. Trans Inst British Geograph NS 30:287-292

Peterson GD, Cumming GS, Carpenter SR (2003) Scenario planning: a tool for conservation in an uncertain world. Conserv Biol 17(2):358-366

Pereira HM, Leadley PW et al (2010) Scenarios for global biodiversity in the twenty-first century. Science 330(6010):1496-1501

Pielke RA Jr (2007) The honest broker. Making sense of science in policy and politics. University Press, Cambridge

Pohl C (2008) From science to policy through transdisciplinary research. Environ Sci Policy 11(8):46-53

Rich RF (1997) Measuring knowledge utilization: process and outcomes. Knowledge and policy. Int J Knowl Transf Util 10(3):11-24

Rosenberg AA (2007) Fishing for certainty. Nature 449(7165):989

Rothman DS, van Bers C, Bakkes J, Pahl-Wostl C (2009) How to make global assessments more effective: lessons from the assessment community. Curr Opin Environ Sustain 1(2):214-218

Rounsevell MDA, Dawson TP, Harrison PA (2010) A conceptual framework to analyse the effects of environmental change on ecosystem services. Biodivers Conserv 19:2823-2842

Roux DJ, Rogers RH, Biggs HC, Ashton PJ, Sergeant A (2006) Bridging the science-management divide moving from unidirectional knowledge transfer to knowledge interfacing and sharing. Ecol Soc. 11(2):37 http://www.ecologyandsociety.org/vol11/iss1/art4/

Sarkki S, Niemelä J, Tinch R, Van den Hove S, Watt AD, Young JC (2013) Balancing credibility, relevance and legitimacy: a critical assessment of trade-offs in science-policy interfaces. Sci \& Public Policy 40(2):171-186

Sharman M, Mlambo MC (2012) Wicked: the problem of biodiversity loss. Gaia 21(4):274-277

Shaxson L, Bielak T (2012) Expanding our understanding of $\mathrm{K}^{*}$ (KT, KE, KTT, KMb, KB, KM, etc.). A concept paper emerging from the $\mathrm{K}^{*}$ conference held in UNU-INWEH Hamilton, ON, April 2012, Hamilton, $30 \mathrm{pp}+$ appendices

Spierenburg M (2012) Getting the message across. Biodiversity science and policy interfaces-A review. Gaia 21(2):125-134

Stirling A (2010) Keep it complex. Nature 468:1029-1031

Strauss AL, Corbin JM (1998) Basics of qualitative research: techniques and procedures for developing grounded theory. Sage Publications, London 
Sutherland WJ, Adams WM, Aronson RB, Aveling R, Blackburn TM, Broad S, Ceballos G, Côté IM, Cowling RM, Da Fonseca GA, Dinerstein E, Ferraro PJ, Fleishman E, Gascon C, Hunter M Jr, Hutton J, Kareiva P, Kuria A, Macdonald DW, Mackinnon K, Madgwick FJ, Mascia MB, McNeely J, MilnerGulland EJ, Moon S, Morley CG, Nelson S, Osborn D, Pai M, Parsons EC, Peck LS, Possingham H, Prior SV, Pullin AS, Rands MR, Ranganathan J, Redford KH, Rodriguez JP, Seymour F, Sobel J, Sodhi NS, Stott A, Vance-Borland K, Watkinson AR (2009) One hundred questions of importance to the conservation of global biological diversity. Conserv Biol 3:557-567

Turnhout E, Hisschemöller M, Eijsackers H (2008) Science on Wadden sea policy: from accommodation to advocacy. Environ Sci Policy 11(3):227-239

Turnhout E, Stuiver M, Klostermann J, Harms B, Leeuwis C (2013) New roles of science in society: different repertoires of knowledge brokering. Sci Public Policy 40:354-365

Van den Hove S (2007) A rationale for science-policy interfaces. Futures 39(7):807-826

Van Kerkhoff L, Lebel L (2006) Linking knowledge and action for sustainable development. Annu Rev Environ Resour 31:445-477

Vogel C, Moser SC, Kasperson RE, Dabelko GD (2007) Linking vulnerability, adaptation, and resilience science to practice: pathways, players, and partnerships. Glob Environ Chang 17:349-364

Wardekker AJ, Van der Sluijs JD, Janssen PHM, Kloprogge P, Petersen AC (2008) Uncertainty communication in environmental assessments: views from the Dutch science-policy interface. Environ Sci Policy 11(7):627-641

Watson RT (2005) Turning science into policy: challenges and experiences from the science-policy interface. Phil Trans R Soc B 360:471-477

Waylen KA, Young J (2014) Expectations and experiences of diverse forms of knowledge use: the case of the UK National Ecosystem Assessment. Environment and Planning C: Government and Policy

White DD, Wutich A, Larson KL, Gober P, Lant T, Senneville C (2010) Credibility, salience, and legitimacy of boundary objects: water managers' assessment of a simulation model in an immersive decision theatre. Sci Public Policy 37(3):219-232

Wynne B, Felt U, Eduarda Goncalves M, Jasanoff S, Jepsen M, Joly P-B, Konopasek Z (2007) Taking European knowledge society seriously. Eur Comm, Brussels

Young J (2007) Bridging research and policy: the RAPID approach. In: Hovland J, Roubaud F (ed) The policy paradox in Africa: strengthening links between Economic Research and policymaking. African World Press, Trenton, p 71

Young J, Marzano M (2010) Embodied interdisciplinarity: what is the role of polymaths in environmental research? Environ Conserv 37(4):373-375

Young JC, Watt AD, Van den Hove S and the SPIRAL project team (2013) Effective interfaces between science, policy and society: the SPIRAL project handbook. 13(2):48 http://www.spiral-project.eu/ content/documents 